\title{
Adrenal vein sampling in the diagnosis of aldosteronism
}

This article was published in the following Dove Press journal:

Journal of Vascular Diagnostics

8 June 2015

Number of times this article has been viewed

\author{
Amy R Deipolyi' \\ Rahmi Oklu² \\ 'Vascular and Interventional \\ Radiology, NYU Langone Medical \\ Center, New York, NY, USA; \\ ${ }^{2}$ Interventional Radiology, \\ Massachusetts General Hospital, \\ Harvard Medical School, Boston, MA, \\ USA
}

\begin{abstract}
Primary aldosteronism causes $15 \%-25 \%$ of cases of drug-resistant hypertension. Adrenal vein sampling (AVS) is a procedure entailing the measurement of aldosterone from both adrenal veins, to diagnose an adrenal source of excess aldosterone secretion. Because unilateral adrenal etiologies of primary aldosteronism may be surgically resected, identifying these sources by venous sampling is critical. Technical aspects of the procedure are reviewed, with emphasis on strategies to avoid common difficulties during AVS.
\end{abstract}

Keywords: primary aldosteronism, hypertension, venous sampling, adrenal adenoma

\section{Introduction}

Hypertension affects more than $25 \%$ of the adult population in the US. ${ }^{1}$ As many as $15 \%$ of all hypertension is due to primary aldosteronism (PA), ${ }^{2-4}$ and this number approaches $25 \%$ when only patients with drug-resistant hypertension are considered. ${ }^{5-7}$ PA may be caused by unilateral or bilateral adrenal pathology. This distinction is critical, as unilateral etiologies are surgically curable, whereas bilateral causes are often medically managed with mineralocorticoid receptor antagonists and additional antihypertensives as required.

Adrenal vein sampling (AVS) is the gold standard test to localize sources of excess aldosterone. AVS can be technically challenging, particularly in centers where it is infrequently performed, although in experienced hands technical success exceeds $90 \%$ and can reliably diagnose the etiology of PA. This review outlines the role of AVS in diagnosing causes of PA, and the technical details involved in assuring reliable sampling.

\section{Pathophysiology of PA}

Aldosterone secretion is regulated by two primary systems: the renin-angiotensinaldosterone system (RAAS) and the hypothalamic-pituitary-adrenal axis (HPAA) (Figure 1). The RAAS involves secretion of renin by renal juxtaglomerular cells in response to stimuli such as decreased renal blood flow. Renin stimulates conversion of angiotensinogen produced in the liver to angiotensin I; ACE produced in the lung in turn stimulates conversion of angiotensin I to II. Angiotensin II then stimulates adrenal cortical secretion of aldosterone. ${ }^{8}$ In a negative feedback loop, aldosterone suppresses renin secretion. Plasma potassium levels also modulate aldosterone secretion; hypokalemia resulting from aldosterone suppresses aldosterone secretion.

Central nervous system regulation of aldosterone levels is via the HPAA: the hypothalamus secretes corticotropin-releasing hormone in response to stimuli such as stress. Corticotropin-releasing hormone stimulates the anterior pituitary to secrete

\footnotetext{
Correspondence: Rahmi Oklu

Vascular and Interventional Radiology,

Massachusetts General Hospital,

55 Fruit Street, 290 Gray/Bigelow,

Boston, MA 02114 , USA

Tel +I 6176436315

Email roklu@mgh.harvard.edu
}

Journal of Vascular Diagnostics 2015:3 17-23 (c) (i) (8) 2015 Deipolyi and Oklu. This work is published by Dove Medical Press Limited, and licensed under Creative Commons Attribution - Non Commercial (unported, v3.0) BY NC License. The full terms of the License are available at http://creativecommons.org/licenses//by-nc/3.0/. Non-commercial uses of the work are permitted without any further permission from Dove Medical Press Limited, provided the work is properly attributed. Permissions beyond the scope of the License are administered by Dove Medical Press Limited. Intormation on
how to request permission may be found at: http://www.dovepress.com/permissions.php 


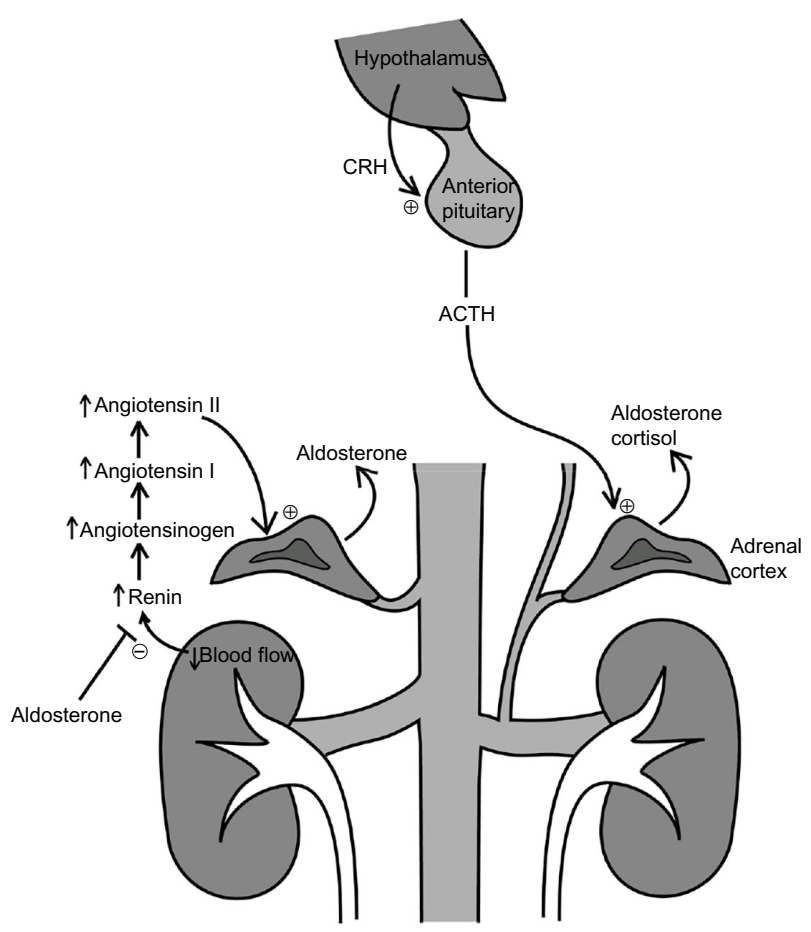

Figure I Physiology and anatomy of adrenal aldosterone secretion.

Notes: Aldosterone secretion is controlled by the RAAS and the HPAA. Renin is secreted by renal juxtaglomerular cells in response to reduced renal blood flow and stimulates production of angiotensin II, which in turn stimulates adrenal cortical secretion of aldosterone. Aldosterone normally negatively regulates renin secretion. Also, in response to $\mathrm{CRH}$ secreted by the hypothalamus, the pituitary secretes ACTH, which in turn stimulates adrenal secretion of aldosterone. Adrenal aldosterone secretion is measured by cannulating both adrenal veins. Whereas the left adrenal vein most often drains into the left renal vein via a common trunk with the inferior phrenic vein, the right adrenal vein drains directly into the posterolateral inferior vena cava. Arrow with - symbol denotes an inhibitory effect, whereas an arrow with a + symbol indicates a stimulatory effect.

Abbreviations: RAAS, renin-angiotensin-aldosterone system; HPAA, hypothalamicpituitary-adrenal axis; ACTH, adrenocorticotropic hormone; $\mathrm{CRH}$, corticotropinreleasing hormone.

adrenocorticotropic hormone (ACTH). ${ }^{9} \mathrm{ACTH}$ in turn stimulates adrenal cortical secretion of cortisol and aldosterone.

PA involves excess secretion of aldosterone by autonomous sources not inhibited by the normal feedback loops. At least seven subtypes of PA are described, with $98 \%$ due to aldosterone-producing adenomas and bilateral adrenal hyperplasia ("idiopathic aldosteronism"), and the other $2 \%$ due to adrenal carcinoma, rare familial subtypes, and unilateral primary adrenal hyperplasia. ${ }^{10}$ Aldosterone-producing adenomas account for $35 \%-40 \%$ of cases, and bilateral adrenal hyperplasia for $60 \% .{ }^{11}$

In PA, excess aldosterone acts on the distal tubule and medullary collecting duct to increase salt reabsorption and potassium excretion. Water reabsorption follows salt, causing volume expansion. Refractory hypertension and possibly hypokalemic metabolic acidosis may ensue. ${ }^{8}$ Clinical presentation is not often specific for hyperaldosteronism, but may include muscle weakness and cramping, palpitations, polyuria and polydipsia, due to hypokalemia. The hypertension of PA is usually moderate to severe and resistant to standard antihypertensive medications. ${ }^{11}$

\section{Non-invasive diagnostic workup}

Workup for PA should be considered for all patients with high blood pressure and hypokalemia (Figure 2).

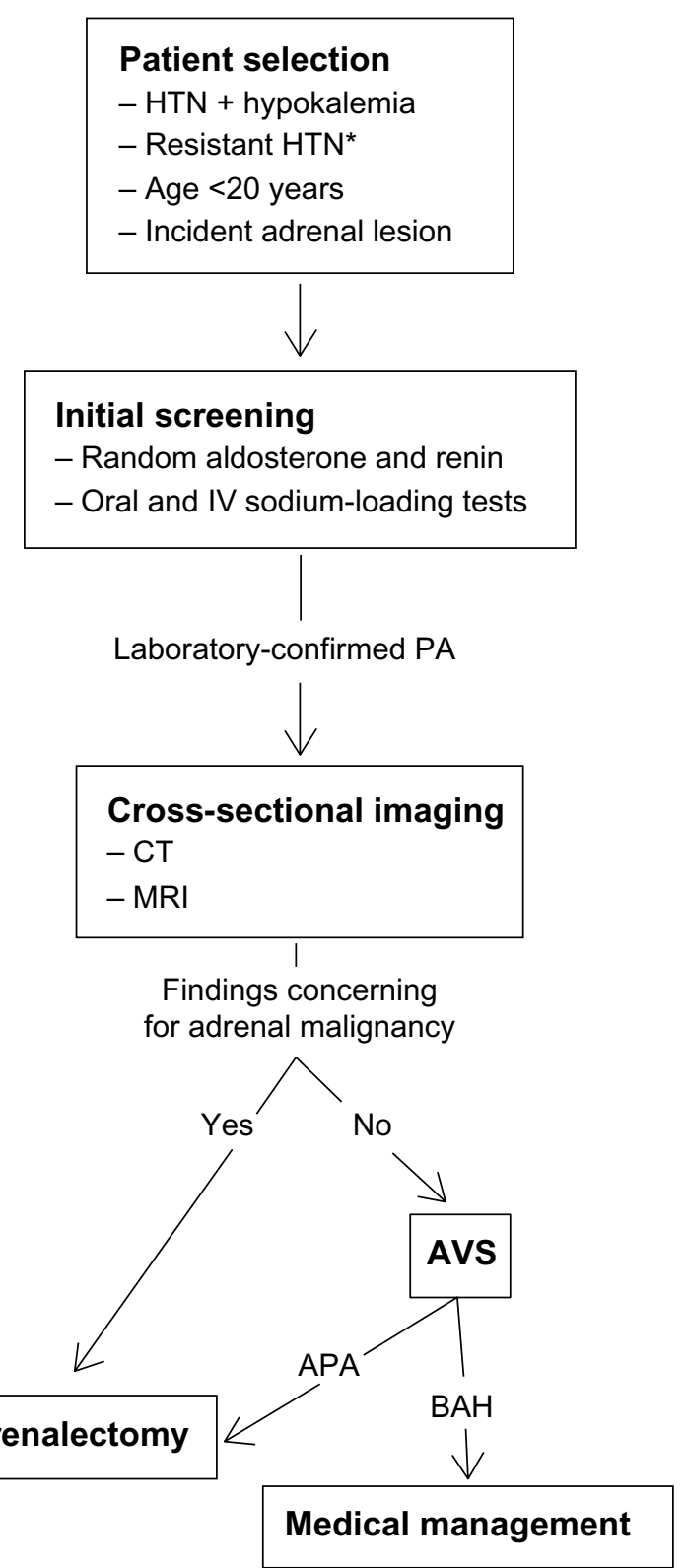

Figure 2 Workup of patients with possible hyperaldosteronism.

Notes: After initial laboratory screening, patients with suspected PA but no crosssectional imaging findings suspicious for adrenal malignancy undergo AVS, which can distinguish unilateral from bilateral adrenal sources of aldosterone. *Resistant HTN: defined as requiring three or more antihypertensive medications.

Abbreviations: APA, aldosterone-producing adenoma; AVS, adrenal vein sampling; $\mathrm{BAH}$, bilateral adrenal hyperplasia; CT, computed tomography; HTN, hypertension; IV, intravenous; MRI, magnetic resonance imaging; PA, primary aldosteronism. 
Other concerning features would be severe hypertension resistant to standard medications, patient age under 20 years, or when an incidental adrenal lesion is detected on crosssectional imaging in a hypertensive patient. According to Endocrine Society guidelines, all patients with moderate/ severe hypertension (systolic blood pressure $>160$, diastolic blood pressure $>100$ ) should also be evaluated for PA. ${ }^{12}$ Treatment resistance is defined as poor blood pressure control despite three or more antihypertensive medications. Because many patients with PA can have normal potassium levels, normokalemia should not contraindicate assessment for PA if secondary causes of hypertension are being considered. ${ }^{11}$

Initial screening includes assessment of paired random plasma aldosterone concentration and plasma renin activity or concentration in the morning (8-10 am) with the patient seated. This test should be performed after potassium levels have been normalized and after mineralocorticoid receptor antagonists such as spironolactone have been discontinued for 2 weeks. The aldosterone:renin ratio is critical, with high ratios suggesting PA. Specific thresholds are laboratory-specific. ${ }^{11}$ Further confirmatory tests include the oral sodium-loading test and intravenous saline infusion test, as aldosterone levels are suppressed after salt loading in normal patients. The oral loading test entails a 3-day high-sodium diet, followed by a 24-hour urine collection to assess aldosterone secretion; high levels in the urine are consistent with an autonomous aldosterone source with sensitivity and specificity of approximately $95 \% .{ }^{13}$ The intravenous infusion test entails administration of a large bolus of normal saline, done after an overnight fast. Plasma aldosterone concentration is then measured, with high levels consistent with PA. ${ }^{14}$ Other confirmatory tests include the fludrocortisone suppression test, captopril challenge, and the seated saline suppression test; there is no current gold standard confirmatory test. ${ }^{12,15}$

Patients with laboratory-confirmed PA are then evaluated with cross-sectional imaging, usually beginning with computed tomography (CT). While cross-sectional imaging can identify large adrenal masses concerning for malignancy, it does not reliably distinguish unilateral from bilateral disease, with nearly $40 \%-50 \%$ of patients misdiagnosed on CT or magnetic resonance imaging (MRI). ${ }^{16,17}$ Sensitivity and specificity of CT and MRI have been reported to be $56 \%$ and $57 \%$, and $60 \%$ and $67 \%$, respectively. ${ }^{18}$ The low diagnostic yield of cross-sectional imaging is due to the high incidence of incidental non-functioning adrenal lesions and the presence of microscopic nodules below the resolution of CT or MRI. ${ }^{19}$ The primary function of cross-sectional imaging is to identify findings concerning for adrenal malignancy, and for pre-procedural planning before AVS.

\section{AVS procedure}

AVS is the gold standard assay to distinguish unilateral from bilateral adrenal sources of autonomous aldosterone secretion. According to consensus guidelines, AVS should be performed in all patients with an established diagnosis of PA in whom adrenalectomy is being considered, except for young (less than 40 years old) patients with severe PA and clear findings on cross-sectional imaging or for patients with findings suspicious for adrenocortical carcinoma. ${ }^{20}$ Similar to preparing for laboratory sodium-loading tests, mineralocorticoid receptor antagonists and amiloride (a potassium-sparing diuretic) should be withheld for several weeks, so as not to confound results.

Sampling is performed from each adrenal vein (AV) and the inferior vena cava (IVC) sequentially, or simultaneously. Simultaneous sampling has the theoretical advantage of eliminating temporal fluctuations in hormone secretion, and necessitates bilateral common femoral venous access. Simultaneous sampling can increase the technical challenge of AVS, as maintaining access in both AVs may prove difficult. These challenges may be minimized with sequential sampling, which is typically performed during infusion of cosyntropin, a synthetic analog of ACTH that stimulates the adrenal gland to secrete cortisol and aldosterone and increases the sensitivity and specificity of AVS. Thus, most centers use sequential sampling with cosyntropin stimulation. ${ }^{21}$ In this technique, a 5 or 6 French vascular sheath is placed in the right common femoral vein, allowing for passage of 4 and 5 French catheters to direct into each AV. A peripheral specimen may be obtained from the IVC or the groin sheath once the AV specimens are collected. Cosyntropin infusion should be initiated at least 30 minutes prior to any sampling.

Because the right AV originates directly from the IVC, whereas the left AV originates from the left renal vein (Figure 3), the right AV is technically more challenging to cannulate 22,23 and is typically assessed first. A variety of catheters may be needed to find the right AV, whereas usually a Simmons- 2 catheter will readily cannulate the left AV. After being advanced into the renal vein, the Simmons catheter can be slowly withdrawn until it falls into the common venous trunk emptying both the inferior phrenic and left AV (Figure 3). Sampling may be performed in the common trunk, or a microcatheter may be used to select the AV. Strategies for finding the right AV are detailed later in the section describing AVS pearls. Catheter position is 


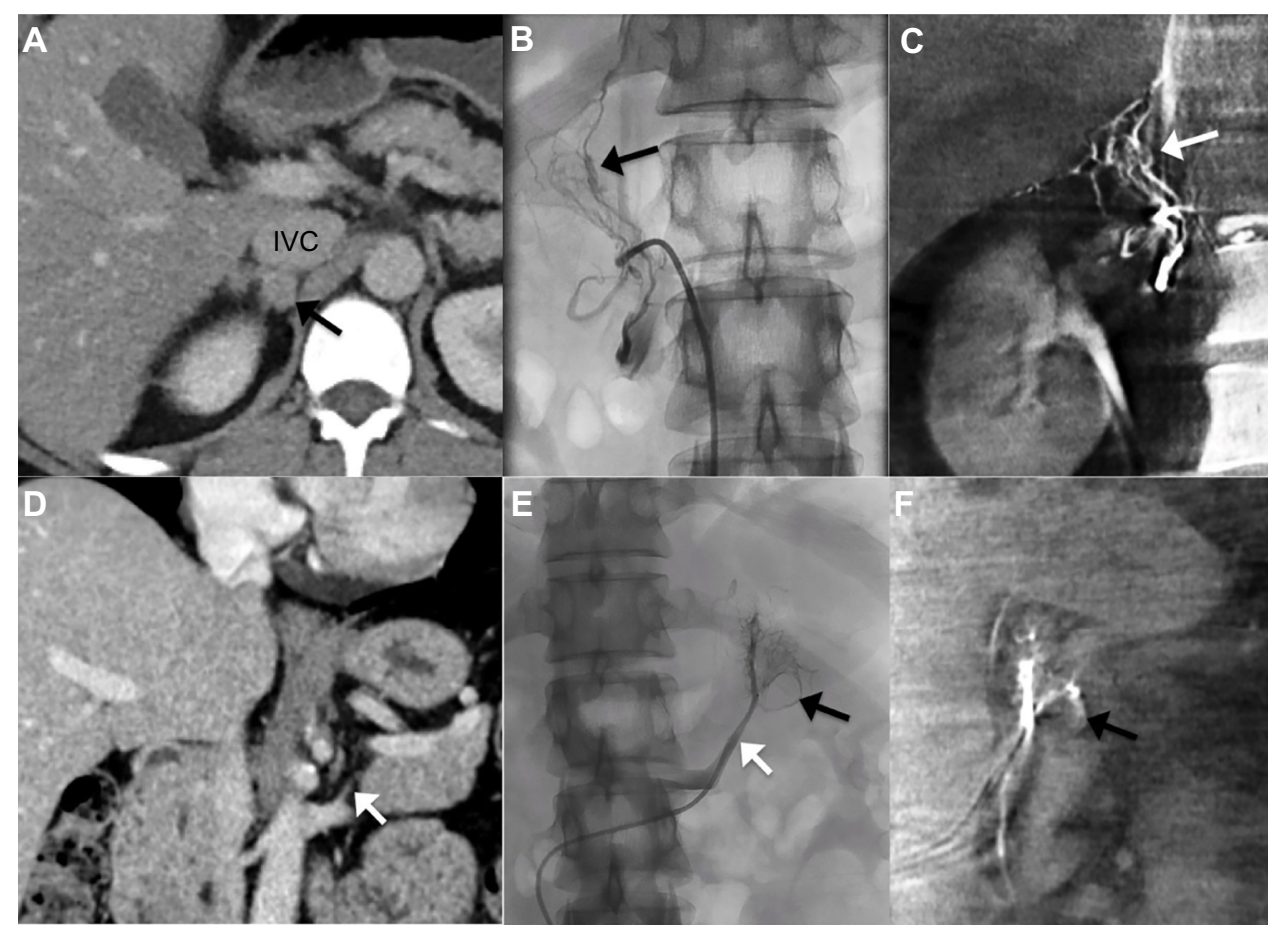

Figure 3 CT and fluoroscopic images from AVS.

Notes: (A-C) Demonstrates an adenoma in the right adrenal gland (D-F) and adenoma in the left adrenal gland. (A) Contrast enhanced CT image revealing an adrenal adenoma (black arrow) abutting the inferior vena cava (IVC) posteriorly. (B) Contrast injection from a 5 French Cobra catheter within the right adrenal vein demonstrating the adenoma (black arrow) seen in image (A). (C) Subsequent real-time cone-beam CT imaging demonstrating the right adrenal gland and the adenoma (white arrow) seen in (A). Cone-beam CT image confirms accurate catheterization of the right adrenal vein. (D) Reformatted coronal CT image showing the origin of the left adrenal vein (white arrow). (E) Corresponding venography image following contrast injection from a microcatheter in the left adrenal vein reveals the origin of the vein (white arrow) similar to image (D) and the adrenal gland including an adenoma (black arrow). (F) Subsequent real-time cone-beam CT imaging confirms correct catheterization of the left adrenal vein also showing the adenoma (black arrow) seen in image (E).

Abbreviations: CT, computed tomography; AVS, adrenal vein sampling.

confirmed with gentle hand injections, and power injections are never performed. Usually, multiple specimens are taken from candidate right AVs, and one or two samples from the left AV and/or common trunk. Specimens should not be transported on ice, but should be maintained in specific tubes requested by the laboratory, agreed upon with laboratory staff prior to the procedure.

Complications from AVS are rare, occurring in less than $1 \%$ of cases when strong adrenal venous injections are avoided. ${ }^{21}$ Major complications include AV hemorrhage which can lead to hemorrhage of the adrenal gland itself, usually presenting as increasing pain after injection persisting for 1-2 days. ${ }^{24}$ Adrenal hemorrhage results in retroperitoneal adhesions that may increase the difficulty of future laparoscopic adrenalectomy. Such complications were more common when powerful injections were used for diagnostic adrenal venography, which is now unnecessary with the availability of cross-sectional imaging. Other major complications including AV thrombosis, hypertensive crisis, and adrenal insufficiency are rare. Complications may be more common among patients with Cushing or Conn Syndrome, owing to the probable increased fragility of the AV noted historically by surgeons performing adrenal explorations. ${ }^{25-27}$ Complications correlate inversely with the number of procedures performed by the operator. ${ }^{21,24}$

In experienced centers, the bilateral $\mathrm{AVs}$ are catheterized and sampled with a technical success rate exceeding $90 \%{ }^{24}$ Technical success is directly associated with operator experience, leading to the recommendation that the procedure be performed by one or two operators at a particular institution to maximize expertise. ${ }^{28}$ The right $\mathrm{AV}$ is technically more challenging to cannulate; suggestions to optimize success are presented later. The procedure may be performed rapidly by experienced interventionalists, with procedure times as low as 7 minutes reported; although, in technically challenging cases or in centers with less experience, the procedure may require up to 2 hours. ${ }^{24}$

\section{AVS results interpretation}

Because the normal adrenal gland produces cortisol in response to ACTH, venous cortisol levels are used as a positive control to determine that the $\mathrm{AV}$ is adequately 
sampled. The cortisol level in each $\mathrm{AV}\left(\mathrm{C}_{\mathrm{AV}}\right)$ is compared to peripheral samples taken from the IVC or right common femoral vein $\left(\mathrm{C}_{\text {peripheral }}\right)$, to generate a ratio $\left(\mathrm{C}_{\mathrm{AV}}: \mathrm{C}_{\text {peripheral }}\right)$, as $\mathrm{CAV}$ cortisol should be several times greater than peripheral levels. A wide range of $\mathrm{C}_{\mathrm{AV}}: \mathrm{C}_{\text {peripheral }}$ index cutoffs have been used, from 1.1 to $5,{ }^{29}$ with most centers using a cutoff of 3 for AVS performed with cosyntropin stimulation, and 2 for AVS performed without stimulation. ${ }^{20}$

Once it has been proven that both left and right AVs have been adequately sampled, the next step is to determine if results are lateralizing to one gland (Table 1). The aldosterone level (A) in each sample is normalized to the cortisol level $\left(\mathrm{A}_{\mathrm{LAV}} / \mathrm{C}_{\mathrm{LAV}}\right.$ and $\left.\mathrm{A}_{\mathrm{RAV}} / \mathrm{C}_{\mathrm{RAV}}\right)$. Then, one side is divided by the other to determine the lateralization index (LI) ${ }^{19,23,30} \mathrm{LI} \geq 4$ is compatible with a unilateral source of aldosterone..$^{20,21}$ Most centers use the LI to diagnose unilateral etiologies of PA; contralateral gland suppression can also confirm the diagnosis. ${ }^{31,32}$

\section{AVS pearls}

Most AVS technical failures are due to difficulty selecting the right $\mathrm{AV}$, which originates directly from the posterolateral IVC. ${ }^{22,23}$ Careful inspection of preprocedural cross-sectional imaging, preferably CT, can often demonstrate the position of the right $\mathrm{AV}$ (Figure $3 \mathrm{~A}$ and D). An initial pigtail catheter inferior vena cavagram in the expected position of the right $\mathrm{AV}$ can sometimes demonstrate the position of the AV origin, as a small focus of contrast pooling. Various catheters may be necessary to cannulate it, including reverse curve catheters and microcatheters. Proper recognition of right adrenal venography patterns is critical: injection may reveal a central stem with branches in a gland-like pattern, a triangular pattern with parenchymal blush, a delta pattern without parenchymal blush, or a central vein with stellate branches (Figure 3B) ${ }^{24}$ Typically, inferolaterally or medially oriented emissary veins will emerge from the RAV from the adrenal capsule and communicate with the renal or phrenic veins, IVC, or intercostal veins. If upward-sloping branches are seen, this suggests cannulation of the accessory hepatic vein. Selecting the inferior accessory hepatic vein is a common occurrence during the search for the right AV; fortunately, this may be used as a helpful anatomic landmark, as the right AV is typically found within $5 \mathrm{~mm}$ of the inferior accessory hepatic vein. ${ }^{33} \mathrm{In}$ addition to recognizing these patterns on venography, intraprocedural cone beam $\mathrm{CT}$ (Figure $3 \mathrm{C}$ and $\mathrm{F}$ ) or rapid cortisol testing may be used to confirm that the right $\mathrm{AV}$ is selected. ${ }^{20}$ When immediately transported to the laboratory, cortisol testing typically requires approximately $0.5-1$ hour. While awaiting these results, the left AV can be sampled.

Not only is the right AV relatively difficult to select, but because of its early branching anatomy, once selected, the end-hole of the catheter is often apposed to a venous bifurcation, preventing aspiration of the catheter to collect the specimen. Furthermore, due to the diminutive nature of the vein, the wall can collapse around the catheter, also inhibiting

Table I Examples of AVS results

\begin{tabular}{|c|c|c|c|c|c|}
\hline & Cortisol (mcg/dL) & Aldosterone (ng/dL) & Cortisol AV:P & $\mathbf{A} / \mathbf{C}$ & LI \\
\hline \multicolumn{6}{|c|}{ Bilateral adrenal hyperplasia } \\
\hline Left AV & 1,110 & 6,450 & 9.3 & 5.8 & 1.2 \\
\hline Right AV & 1,350 & 6,600 & 11.3 & 4.9 & 0.8 \\
\hline Peripheral & 120 & 367 & & & \\
\hline \multicolumn{6}{|c|}{ Right adrenal aldosterone-secreting adenoma } \\
\hline Left AV & 1,020 & 640 & 8.5 & 0.6 & 0.1 \\
\hline Right AV & $\mathrm{I}, 130$ & 6,800 & 9.4 & 6.0 & 9.6 \\
\hline Peripheral & 120 & 385 & & & \\
\hline \multicolumn{6}{|c|}{ Left adrenal aldosterone-secreting adenoma } \\
\hline Left AV & 1,220 & 6,840 & 10.2 & 5.6 & 12.9 \\
\hline Right AV & 1,310 & 570 & 10.9 & 0.4 & 0.1 \\
\hline Peripheral & 120 & 345 & & & \\
\hline \multicolumn{6}{|c|}{ Non-diagnostic study (failed right AV cannulation) } \\
\hline Left $A V$ & 1,110 & 6,450 & 9.3 & 5.8 & \\
\hline Right AV & 130 & 420 & 11.3 & 4.9 & \\
\hline Peripheral & 120 & 410 & & & \\
\hline
\end{tabular}

Notes: Cortisol AV:P calculated as the ratio of the cortisol level in the ipsilateral AV divided by the cortisol level in the peripheral vein; $\mathrm{A} / \mathrm{C}$ : normalized aldosterone level, calculated as aldosterone level divided by cortisol level. LI calculated as A/C of the ipsilateral divided by contralateral side. AVS is considered diagnostic when both left and right cortisol AV:P ratios are $\geq 3$ (AVS with hormone stimulation). $\mathrm{LI} \geq 4$ is considered evidence of a unilateral aldosterone-secreting adrenal lesion. When one $\mathrm{AV}$ is not successfully cannulated, as in the last example, the AVS is considered non-diagnostic and the LI cannot be calculated.

Abbreviations: AVS, adrenal vein sampling; AV, adrenal vein; LI, lateralization index; P, peripheral; A/C, aldosterone/cortisol. 
aspiration. Strategies to allow for collection of the requisite 5-6 cc of venous blood include: using catheters with side holes near the tip, which may be created using 22-gauge needles; intermittent gentle suction using a syringe with air within it to reduce the negative pressure; allowing blood to drop slowly into a sample bottle rather than aspirating. ${ }^{24}$

The left AV is most often a branch of the left renal vein, and shares a common trunk with the inferior phrenic vein (Figure 3E). The left AV is most often selected with a reverse curve catheter, such as a Simmons catheter, which may be advanced peripherally in the renal vein over a glidewire, then retracted until the tip carefully pops into the common trunk. Sampling may be performed from the common trunk, or from the AV using a microcatheter.

Failure to select the left AV, however, accounts for nearly a third of technical failures. ${ }^{34}$ Challenges in cannulating the left AV are primarily due to aberrant venous anatomy. Bilateral IVCs are present in less than $1 \%$ of patients, but left AV variants are present in $10 \%$ of people, most commonly circumaortic (6\%), and less commonly retroaortic renal veins (4\%) which are typically significantly more inferior from the IVC. ${ }^{35}$ Careful inspection of preprocedural cross-sectional imaging is essential to prepare for AVS in these cases.

Many centers utilize a sequential method with cosyntropin stimulation, as described earlier. Bilateral simultaneous sampling carries the theoretical benefit of minimizing the effect of hormone fluctuations over time, however is more technically challenging, as stable venous access to both AVs must be maintained. Given the more prolonged venous catheterization, intravenous heparin should be considered. Furthermore, if no cosyntropin is administered, careful attention to behavioral relaxation to minimize stress-related hormonal fluctuation is warranted. ${ }^{20}$

\section{Conclusion and future perspectives}

In conclusion, AVS is a safe procedure with a high technical success rate among experienced operators. It is the gold standard test in diagnosing unilateral sources of aldosterone in patients with PA and is indicated in all patients who are surgical candidates for potentially curative adrenalectomy. A number of strategies can assist in increasing the probability of a diagnostic exam and reduce the possibility of complications.

Assuming a population of 320 million US citizens, with more than $25 \%$ of people affected by hypertension ${ }^{1}$ and $15 \%$ of these cases due to $\mathrm{PA},{ }^{2-4}$ one may estimate 12 million people who may have an indication for AVS. As $40 \%$ of these would be expected to be due to aldosterone-producing adenomas and the vast majority of patients are cured after adrenalectomy, we can estimate that over 4 million patients could be diagnosed with AVS and surgically cured. Close collaboration with endocrinologists and surgeons is warranted to allow interventional radiologists to help in treating these patients.

\section{Disclosure}

The authors report no conflicts of interest.

\section{References}

1. Egan BM, Zhao Y, Axon RN. US trends in prevalence, awareness, treatment, and control of hypertension, 1988-2008. JAMA. 2010;303(20): 2043-2050.

2. Gordon RD, Stowasser M, Tunny TJ, Klemm SA, Rutherford JC. High incidence of primary aldosteronism in 199 patients referred with hypertension. Clin Exp Pharmacol Physiol. 1994;21(4):315-318.

3. Lim PO, Rodgers P, Cardale K, Watson AD, MacDonald TM. Potentially high prevalence of primary aldosteronism in a primary-care population. Lancet. 1999;353(9146):40.

4. Plouin PF, Amar L, Chatellier G. Trends in the prevalence of primary aldosteronism, aldosterone-producing adenomas, and surgically correctable aldosterone-dependent hypertension. Nephrol Dial Transplant. 2004;19(4):774-777.

5. Calhoun DA, Nishizaka MK, Zaman MA, Thakkar RB, Weissmann P. Hyperaldosteronism among black and white subjects with resistant hypertension. Hypertension. 2002;40(6):892-896.

6. Pilz S, Tomaschitz A, Stepan V, et al. Graz Endocrine Causes of Hypertension (GECOH) study: a diagnostic accuracy study of aldosterone to active renin ratio in screening for primary aldosteronism. $B M C$ Endocr Disord. 2009;9:11.

7. Calhoun DA. Is there an unrecognized epidemic of primary aldosteronism? Pro. Hypertension. 2007;50(3):447-453.

8. Tomaschitz A, Pilz S, Ritz E, Obermayer-Pietsch B, Pieber TR. Aldosterone and arterial hypertension. Nat Rev Endocrinol. 2010;6(2): 83-93.

9. Deipolyi A, Karaosmanoglu A, Habito C, et al. The role of bilateral inferior petrosal sinus sampling in the diagnostic evaluation of Cushing syndrome. Diagn Interv Radiol. 2012;18(1):132-138.

10. Vonend O, Ockenfels N, Gao X, et al. Adrenal venous sampling: evaluation of the German Conn's registry. Hypertension. 2011;57(5): 990-995.

11. Young WF. Primary aldosteronism: renaissance of a syndrome. Clin Endocrinol $(O x f)$. 2007;66(5):607-618.

12. Funder JW, Carey RM, Fardella C, et al. Case detection, diagnosis, and treatment of patients with primary aldosteronism: an endocrine society clinical practice guideline. J Clin Endocrinol Metab. 2008;93(9): 3266-3281.

13. Bravo EL, Tarazi RC, Dustan HP, et al. The changing clinical spectrum of primary aldosteronism. Am J Med. 1983;74(4):641-651.

14. Kem DC, Weinberger MH, Mayes DM, Nugent CA. Saline suppression of plasma aldosterone in hypertension. Arch Intern Med. 1971;128(3): 380-386.

15. Ahmed AH, Cowley D, Wolley M, et al. Seated saline suppression testing for the diagnosis of primary aldosteronism: a preliminary study. J Clin Endocrinol Metab. 2014;99(8):2745-2753.

16. Kempers MJ, Lenders JW, van Outheusden L, et al. Systematic review: diagnostic procedures to differentiate unilateral from bilateral adrenal abnormality in primary aldosteronism. Ann Intern Med. 2009;151(5): 329-337.

17. Nwariaku FE, Miller BS, Auchus R, et al. Primary hyperaldosteronism: effect of adrenal vein sampling on surgical outcome. Arch Surg. 2006;141(5):497-502. 
18. Vonend O, Stegbauer J, Kokulinsky P, et al. Vergleich von Bildgebung und seitengetrennter Nebennierenvenen-Blutentnahme zur Differentialdiagnose bei primärem Hyperaldosteronismus. [Comparison of adrenal imaging and selective adrenal vein sampling in primary hyperaldosteronism]. Dtsch Med Wochenschr. 2007;132(46):2436-2441. German.

19. Young WF, Stanson AW, Thompson GB, Grant CS, Farley DR, van Heerden JA. Role for adrenal venous sampling in primary aldosteronism. Surgery. 2004;136(6):1227-1235.

20. Rossi GP, Auchus RJ, Brown M, et al. An expert consensus statement on use of adrenal vein sampling for the subtyping of primary aldosteronism. Hypertension. 2014;63(1):151-160.

21. Rossi GP, Barisa M, Allolio B, et al. The Adrenal Vein Sampling International Study (AVIS) for identifying the major subtypes of primary aldosteronism. J Clin Endocrinol Metab. 2012;97(5): 1606-1614.

22. Reznek RH, Armstrong P. The adrenal gland. Clin Endocrinol (Oxf). 1994;40(5):561-576.

23. Young WF Jr, Klee GG. Primary aldosteronism. Diagnostic evaluation. Endocrinol Metab Clin North Am. 1988;17(2):367-395.

24. Daunt N. Adrenal vein sampling: how to make it quick, easy, and successful. Radiographics. 2005;25 Supp1 1:S143-S158.

25. Bookstein JJ. The roles of angiography in adrenal disease. In: Abrhams HL, editor. Abram's Angiography. 3rd ed. Boston: Little, Brown; 1983: 1395-1424.

26. Bookstein JJ, Conn J, Reuter SR. Intra-adrenal hemorrhage as a complication of adrenal venography in primary aldosteronism. Radiology. 1968;90(4):778-779.

27. Nesbit RM. The role of the surgeon in the management of normokalemic primary aldosteronism. Surg Gynecol Obstet. 1966;122(1):114-116.
28. Young WF, Stanson AW. What are the keys to successful adrenal venous sampling (AVS) in patients with primary aldosteronism? Clin Endocrinol (Oxf). 2009;70(1):14-17.

29. Magill SB, Raff H, Shaker JL, et al. Comparison of adrenal vein sampling and computed tomography in the differentiation of primary aldosteronism. J Clin Endocrinol Metab. 2001;86(3):1066-1071.

30. Rossi GP, Sacchetto A, Chiesura-Corona M, et al. Identification of the etiology of primary aldosteronism with adrenal vein sampling in patients with equivocal computed tomography and magnetic resonance findings: results in 104 consecutive cases. J Clin Endocrinol Metab. 2001;86(3):1083-1090.

31. Doppman JL, Gill JR Jr, Miller DL, et al. Distinction between hyperaldosteronism due to bilateral hyperplasia and unilateral aldosteronoma: reliability of CT. Radiology. 1992;184(3):677-682.

32. Espiner EA, Ross DG, Yandle TG, Richards AM, Hunt PJ. Predicting surgically remedial primary aldosteronism: role of adrenal scanning, posture testing, and adrenal vein sampling. J Clin Endocrinol Metab. 2003;88(8):3637-3644.

33. Trerotola SO, Smoger DL, Cohen DL, Fraker DL. The inferior accessory hepatic vein: an anatomic landmark in adrenal vein sampling J Vasc Interv Radiol. 2011;22(9):1306-1311.

34. Trerotola SO, Asmar M, Yan Y, Fraker DL, Cohen DL. Failure mode analysis in adrenal vein sampling: a single-center experience. J Vasc Interv Radiol. 2014;25(10):1611-1619.

35. Trigaux JP, Vandroogenbroek S, De Wispelaere JF, Lacrosse M, Jamart J. Congenital anomalies of the inferior vena cava and left renal vein: evaluation with spiral CT. J Vasc Interv Radiol. 1998;9(2):339-345.
Journal of Vascular Diagnostics

\section{Publish your work in this journal}

Journal of Vascular Diagnostics is an international, peer-reviewed journal of diagnostics, focusing on non invasive vascular investigation methods involved in the evaluation of vascular diseases. The journal is committed to the rapid publication in the fields of vascular diseases. Original research, review, case reports, expert opinion and commentaries

\section{Dovepress}

are all considered for publication. The manuscript management system is completely online and includes a very quick and fair peer-review system, which is all easy to use. Visit http://www.dovepress.com/ testimonials.php to read real quotes from published authors. 